\title{
Comparison of the Modified Adomian Decomposition Method and the Simplified Runge-Kutta Method for Solutions of the Anaerobic Digestion Process
}

\author{
Marline Ilha da Silva ${ }^{1}$ \\ Graduate Program in Applied Mathematics, UFRGS, Porto Alegre, RS \\ Álvaro Luiz de Bortoli ${ }^{2}$ \\ Graduate Program in Applied Mathematics, UFRGS, Porto Alegre, RS \\ Graduate Program in Chemical Engineering, UFRGS, Porto Alegre, RS
}

\begin{abstract}
The model that describes the transformation of biomass into biogas, a process called Anaerobic Digestion, is complex because it involves nonlinear and coupled ordinary differential equations. In this way, obtaining an analytical-numerical solution becomes attractive for this problem. In this paper, the chemical kinetics of the anaerobic digestion process is modelade. The system of equations of the model was solved by the Modified Adomian Decomposition Method, a powerful technique used for solve systems of linear and nonlinear differential equations, since it is computationally convenient, precise and physically realistic. The results are compared with the data obtained by the second-order Simplified Runge-Kutta method, and they agree well with each other.
\end{abstract}

Keywords. Anaerobic digestion, Biogas, Simplified Runge-Kutta, Adomian decomposition method

\section{Introduction}

Anaerobic digestion (AD) is a biochemical biogas production process. Biogas is a biofuel composed mainly by methane and carbon dioxide [16]. In this process, biofuel is formed from the biological degradation of biomass [15], the world's most abundant raw material consisting of substances of organic origin, such as plant, animal and microorganisms.

Anaerobic digestion is a complex process, consisting of several stages of metabolic interactions, in the absence of oxygen, and performed by a well-organized community of microbial populations [5,11]. The mathematical model is obtained according to the number of chemical reactions presented in each stage of the process. This modeling provides a set of coupled and nonlinear ordinary differential equations.

The Adomian Decomposition Method (ADM) is a powerful technique used to solve this problem, which involves the writing of nonlinear terms in a series of polynomials.

\footnotetext{
${ }^{1}$ marline.ilhadasilva@gmail.com

2dbortoli@mat.ufrgs.br
} 
Adomian [2] demonstrated that with the ADM technique it is possible solve linear and nonlinear differential equations, obtaining continuous solutions.

Currently, the ADM technique has been used by many authors in several areas to solve problems of linear and nonlinear equations, involving initial and/or boundary conditions $[3,9,10]$. In addition, this technique can be used to solve systems of nonlinear differential equations and also to the solution of higher-order differential equations $[4,8]$. Some researchers have introduced modifications in the ADM technique $[1,7]$. For example, Younker [14] modified the ADM to solve a system of coupled differential equations describing chemical reaction rates.

In this work, a chemical and mathematical model of the AD process is developed, where cellulose is the substrate. In addition, we simulate this process by solving the system of ordinary differential equations by the Modified Adomian Decomposition, applied to the time variable [14], and Simplified Runge-Kutta [6] methods. The two approximations to the solution are compared and one concludes that they agree well.

\section{Chemical and mathematical modeling}

The phases and reactions of the anaerobic digestion process are:

(I) Hydrolysis:

$$
\mathrm{C}_{6} \mathrm{H}_{10} \mathrm{O}_{5}+\mathrm{H}_{2} \mathrm{O} \rightarrow \mathrm{C}_{6} \mathrm{H}_{12} \mathrm{O}_{6}
$$

(II) Acidogenesis:

$$
\mathrm{C}_{6} \mathrm{H}_{12} \mathrm{O}_{6} \rightarrow \mathrm{C}_{4} \mathrm{H}_{8} \mathrm{O}_{2}+2 \mathrm{CO}_{2}+2 \mathrm{H}_{2}, \quad \Delta \mathrm{G}=-264,19 \mathrm{KJ} / \mathrm{mol}
$$

\section{(III) Acetogenesis:}

$$
2 \mathrm{C}_{4} \mathrm{H}_{8} \mathrm{O}_{2}+2 \mathrm{H}_{2} \mathrm{O}+\mathrm{CO}_{2} \rightarrow 4 \mathrm{C}_{2} \mathrm{H}_{4} \mathrm{O}_{2}+\mathrm{CH}_{4}, \quad \Delta \mathrm{G}=-35 \mathrm{KJ} / \mathrm{mol} .
$$

(IV) Hydrogenotrophic methanogenesis:

$$
4 \mathrm{H}_{2}+\mathrm{CO}_{2} \rightarrow \mathrm{CH}_{4}+2 \mathrm{H}_{2} \mathrm{O}, \quad \Delta \mathrm{G}=-131 \mathrm{KJ} / \mathrm{mol}
$$

\section{(V) Acetoclastic methanogenesis:}

$$
\mathrm{C}_{2} \mathrm{H}_{4} \mathrm{O}_{2} \rightarrow \mathrm{CH}_{4}+\mathrm{CO}_{2}, \quad \Delta \mathrm{G}=-36 \mathrm{KJ} / \mathrm{mol} .
$$

More details on each phase can be found in [12].

Table 1 shows the chemical compounds involved in the anaerobic digestion process, described above. Each chemical compound is associated with its chemical formula and abbreviations. 
Tabela 1: Chemical compounds, chemical formulas and abbreviations.

\begin{tabular}{llc}
\hline Chemical compounds & Chemical formulas & Abbreviations \\
\hline Cellulose & $\mathrm{C}_{6} \mathrm{H}_{10} \mathrm{O}_{5}$ & $Y_{1}$ \\
Glucose & $\mathrm{C}_{6} \mathrm{H}_{12} \mathrm{O}_{6}$ & $Y_{2}$ \\
Butyric acid & $\mathrm{C}_{4} \mathrm{H}_{8} \mathrm{O}_{2}$ & $Y_{3}$ \\
Acetic acid & $\mathrm{C}_{2} \mathrm{H}_{4} \mathrm{O}_{2}$ & $Y_{4}$ \\
Methane & $\mathrm{CH}_{4}$ & $Y_{5}$ \\
Carbon dioxide & $\mathrm{CO}_{2}$ & $Y_{6}$ \\
Hidrogen & $\mathrm{H}_{2}$ & $Y_{7}$ \\
Water & $\mathrm{H}_{2} \mathrm{O}$ & $Y_{8}$ \\
\hline
\end{tabular}

The mathematical formulation of the anaerobic digestion process is associated to the phases described above: (I), (II), (III), (IV), and (V). The mathematical model provides a set of ordinary differential equations, called kinetic system of ordinary differential equations (ODEs) (see [13]).

The kinetic system of ODEs and its initial values provides the following initial value problem:

$$
\left\{\begin{array}{ll}
\frac{d Y_{1}}{d t}=-k_{0} Y_{1} Y_{8}, & Y_{1}(0)=1 \\
\frac{d Y_{2}}{d t}=k_{0} Y_{1} Y_{8}-k_{1} Y_{2}, & Y_{2}(0)=0 \\
\frac{d Y_{3}}{d t}=k_{1} Y_{2}-k_{2} Y_{3} Y_{8} Y_{6}^{1 / 2}, & Y_{3}(0)=0 \\
\frac{d Y_{4}}{d t}=2 k_{2} Y_{3} Y_{8} Y_{6}^{1 / 2}-2 k_{4} Y_{4}^{2}, & Y_{4}(0)=0 \\
\frac{d Y_{5}}{d t}=\frac{1}{2} k_{2} Y_{3} Y_{8} Y_{6}^{1 / 2}+\frac{1}{2} k_{3} Y_{6}^{1 / 2} Y_{7}^{2}+2 k_{4} Y_{4}^{2}, & Y_{5}(0)=0 \\
\frac{d Y_{6}}{d t}=2 k_{1} Y_{2}-\frac{1}{2} k_{2} Y_{3} Y_{8} Y_{6}^{1 / 2}-\frac{1}{2} k_{3} Y_{6}^{1 / 2} Y_{7}^{2}+2 k_{4} Y_{4}^{2}, & Y_{6}(0)=0 \\
\frac{d Y_{7}}{d t}=2 k_{1} Y_{2}-2 k_{3} Y_{6}^{1 / 2} Y_{7}^{2}, & Y_{7}(0)=0 \\
\frac{d Y_{8}}{d t}=-k_{0} Y_{1} Y_{8}-k_{2} Y_{3} Y_{8} Y_{6}^{1 / 2}+k_{3} Y_{6}^{1 / 2} Y_{7}^{2}, & Y_{8}(0)=1
\end{array} .\right.
$$

\section{Solution of the problem}

The system (1)are solved by two methods:

1) Modified Adomian Decomposition (Modified ADM) 
The solution is obtained with a truncated series of Adomian polynomials, using the Adomian decomposition method, applied to the time variable [14].

2) Second-order Simplified Runge-Kutta method (RKsimp)

This method provides a good approximation for the solution of systems of coupled equations and is characterized by the small number of operations performed [6].

\section{Results and discussion}

Assume that $k_{0}=1$ and the constants $k_{1}, k_{2}, k_{3}$ and $k_{4}$ are estimated using the Gibbs free energy value $\left(\Delta \mathrm{G}^{\mathrm{o}}\right)$ (see $\left.[13]\right)$.

The simulation is performed using the Modified Adomian and Simplified Runge-Kutta methods, considering $h=0.1$. Figure 1 (a) shows the solution obtained for biogas production. It is shown that biogas production increases rapidly in the first days of the process. After that, the solution slowly tends to the value six, indicating that the methanogenic phase continues for about 50 days. Figure 1 (b) show the errors

$$
E_{\infty}^{B}=\max \left|Y_{B}-\tilde{Y}_{B}\right|,
$$

where $Y_{B}$ and $\tilde{Y}_{B}$ are the biogas concentrations vector using Modified ADM and RKsimp, respectively.

The errors are calculated for different values of $h$ (for different numbers of mesh points). The objective is to compare the two solutions by calculating the difference between them when the number of points of the mesh increases. It is observed that the errors decrease as the spacing between the points decreases, showing that there is agreement between the two solutions.

\section{Conclusions}

In this work, we developed a model for the biogas production process, considering cellulose as substrate. With the Gibbs free energy value $(\Delta \mathrm{G})$, the production rate of each reaction is estimated.

The anaerobic decomposition of glucose, as a cellulose product at $100 \%$ substrate, is possibly given as a whole by $\mathrm{C}_{6} \mathrm{H}_{12} \mathrm{O}_{6}=3 \mathrm{CH}_{4}+3 \mathrm{CO}_{2}$, i.e, with $1 \mathrm{kmol}$ of $100 \%$ glucose, 6 $\mathrm{kmol}$ of biogas can be produced, which is consistent with the results obtained. This shows that, with a computationally simple model, we can solve the coupled set of nonlinear ordinary differential equations, obtained from the anaerobic digestion problem.

In addition, the Modified ADM solution, used for comparison with numerical results, is an important contribution of the present study. 


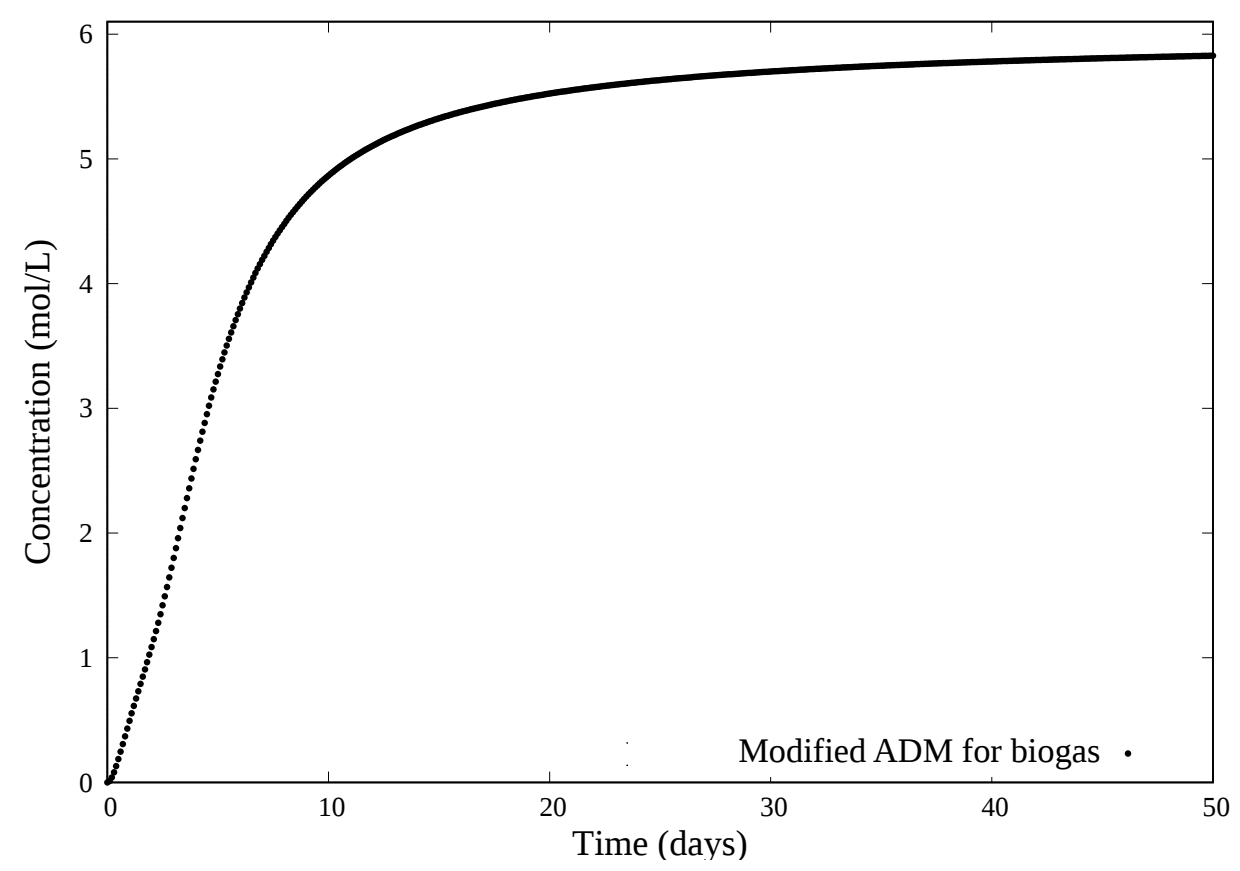

(a) Concentration of biogas obtained by the Modified ADM.

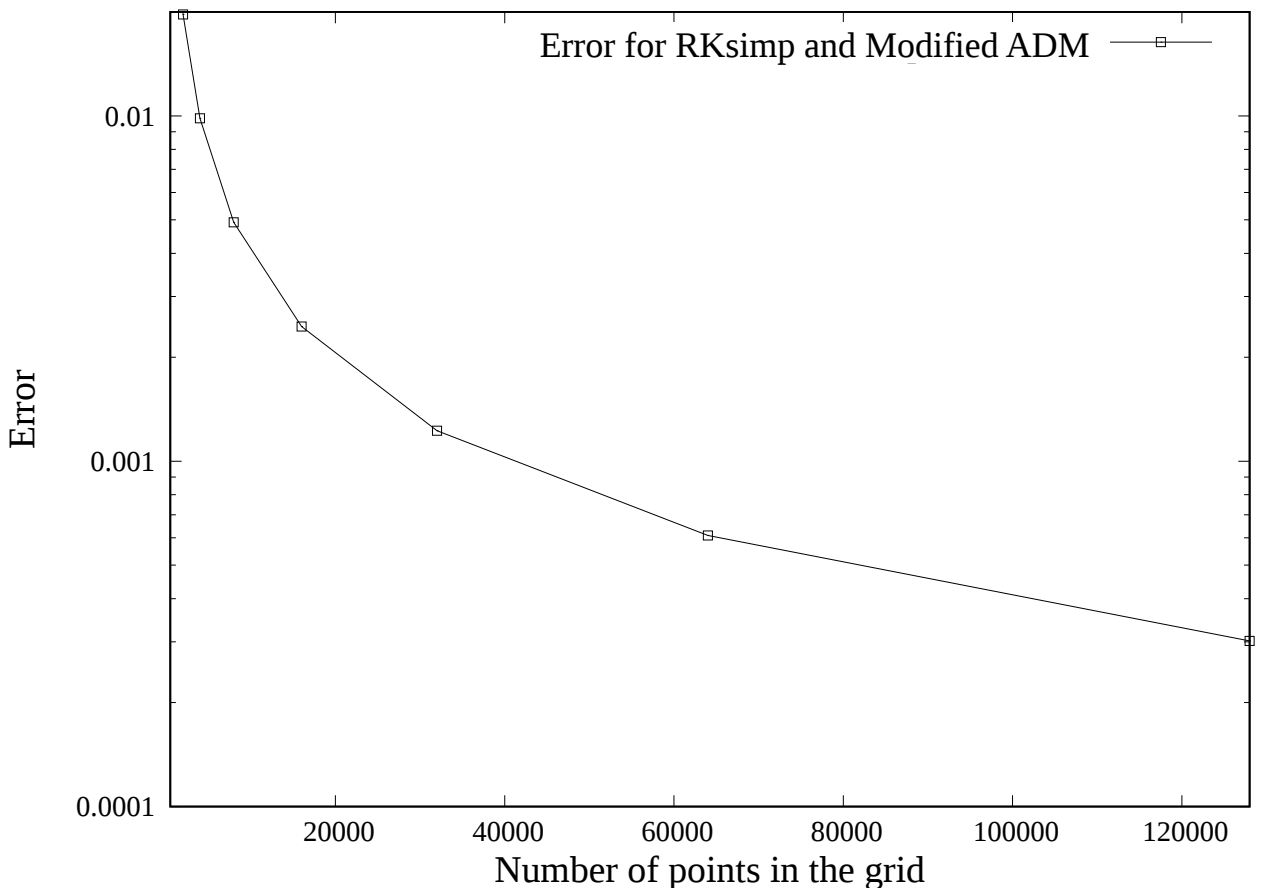

(b) Difference between Modified ADM and RKsimp.

Figura 1: Simulations for the biogas production process. 


\section{Acknowledgements}

This research is being developed at the Federal University of Rio Grande do Sul UFRGS. The author M. I. Silva thanks the financial support of CAPES - Coordenação de Aperfeiçoamento de Pessoal de Nivel Superior - Brazil. Professor De Bortoli gratefully acknowledges the financial support of CNPq - Conselho Nacional de Desenvolvimento Científico e Tecnológico, under grant 303816/2015-5.

\section{Referências}

[1] S. Abbasbandy, and M. T. Darvishi. A numerical solution of Burgers equation by time discretization of Adomian's decomposition method, Applied Mathematics and Computation, 170:95-102, 2005.

[2] G. Adomian. Analytic solutions for nonlinear equations, Applied Mathematics and Computation, 26: 77-88, 1988.

[3] J. Biazar, M. Tango, E. Babolian, and R. Islam. Solution of the kinetic modeling of lactic acid fermentation using Adomian decomposition method, Applied Mathematics and Computation, 144:433-439, 2003.

[4] J. Biazar, E. Babolian, and R. Islam. Solution of the system of ordinary differential equations by Adomian decomposition method, Applied Mathematics and Computation, 147:713-719, 2004.

[5] L. Bjornsson. Intensification of the biogas process by improved process monitoring and biomass retention. Ph.D. thesis, Department of Biotechnology, Lund University, Sweden, 2000.

[6] A. L. Bortoli, G. S. L. Andreis, and F. N. Pereira. Modeling and simulation of reactive flows. Elsevier Science Publishing Co Inc., 2015.

[7] F. Chen, and Q. Liu. Modified asymptotic Adomian decomposition method for solving Boussinesq equation of groundwater flow, Applied Mathematics and Mechanics, 35:481-488, 2014.

[8] H. Gu, and Z. Li. A modified Adomian method for system of nonlinear differential equations. Applied Mathematics and Computation, 187:748-755, 2007.

[9] H. Huang and T. S. Lee. On the Adomian decomposition method for solving the Stefan problem. International Journal of Numerical Methods for Heat and Fluid Flow, 25:912-928, 2015.

[10] D. Kaya, and A. Yokus, A numerical comparison of partial solutions in the decomposition method for linear and nonlinear partial differential equations. Mathematics and Computers in Simulation, 60:507-512, 2002. 
[11] Z. Prokopová, and R. Prokop, Modelling and simulation of dry anaerobic fermentation. In European Conference on Modelling and Simulation, 2010.

[12] M. Silva, and A. L. Bortoli, Modelagem e Simulação do Processo de Formação do Biogás. In Anais do Congresso Nacional de Matemática Aplicada e Computacional (XXXVII CNMAC), São José dos Campos, São Paulo, Brasil, 2017.

[13] M. Silva, and A. L. Bortoli, Simulation of biogas production from the anaerobic digestion process. In Anais do Iberian Latin American Congress on Computational Methods in Engineering (XXXVIII CILAMCE), Florianópolis, Santa Catarina, Brasil, 2017.

[14] J. M. Younker, Numerical integration of the chemical rate equations via a discretized Adomian decomposition. Industrial and Engineering Chemistry Research, 50:31003109, 2011.

[15] L.Yu, Simulation of flow, mass transfer and bio-chemical reactions in anaerobic digestion. Ph.D. thesis, Department of Biological Systems Engineering, Faculty of Washington State University, 2012.

[16] K. Ziemiński, and M. Frac, Methane fermentation process as anaerobic digestion of biomass: Transformations, stages and microorganisms. African Journal of Biotechnology, 11: 4127-4139, 2012. 